\title{
Microbial and inflammatory parameters during the process of non-surgical treatment of Peri- implantitis: Topical minocycline application
}

Yee Mon Shwe ( $\nabla$ yeemonshwe81@gmail.com )

Tokyo Ika Shika Daigaku - Yushima Campus https://orcid.org/0000-0001-8802-8777

Kensuke Inoue

Tokyo Ika Shika Daigaku

Maiko Yamamoto

Tokyo Medical and Dental University

Nakata Hidemi

Tokyo Ika Shika Daigaku

Shinji Kuroda

Tokyo Ika Shika Daigaku

Shohei Kasugai

Tokyo Ika Shika Daigaku

Research article

Keywords: Peri-implantitis, Minocycline, Red-complex pathogens, Non-surgical treatment

Posted Date: January 16th, 2020

DOI: https://doi.org/10.21203/rs.2.21026/v1

License: (c) (1) This work is licensed under a Creative Commons Attribution 4.0 International License.

Read Full License 


\section{Abstract}

The authors have requested that this preprint be removed from Research Square. 